\title{
Hva vet vi om sikring av bru som selvmordsforebyggende tiltak?
}

Ved Aleksandra Sæheim og Ingebjørg Hestetun

\section{Kan sikring av bruer hindre selvmordsnære personer i å ta sitt liv? Hva vet vi om virkning av brusikring, og hvilken betydning har dette for norske forhold?}

\section{ABSTRACT}

Hvert år tar en rekke mennesker livet sitt i Norge ved å hoppe fra et høyt sted. I perioden 2000-2011 har til sammen 324 mennesker tatt sitt eget liv på denne måten. I den statistikken som er tilgjengelig er det ikke spesifisert hvor disse personene har hoppet fra. Rapporter om enkeltstående hendelser gir imidlertid grunn til å anta at selvmord ved hopp fra bruer representerer en betydelig andel av alle selvmord ved utsprang. Et viktig spørsmål er derfor om vi, ved å installere høye gjerder eller andre sikringstiltak på utsatte bruer, kan forebygge selvmord? Internasjonal forskning tyder på dette, og spørsmålet om brusikring diskuteres både i den offentlige debatten og hos vegmyndighetene i Norge. Men det er uklart i hvilken grad kunnskap og erfaringer fra andre land kan overføres til vårt land. I artikkelen tar vi opp relevant forskning, drøfter arbeid med sikring av bruer i Norge, samt orienterer om et igangsatt forskningsprosjekt som vil belyse muligheten til å forebygge selvmord ved sikring av utsatte bruer i Norge.

Every year many Norwegians commit suicide by jumping. In the period 2000-2011 suicide by jumping accounted for 324 deaths. The available statistics does not specify the type of site from which the jumping occurs; however reports of several single incidents give reasons to believe that bridges are commonly used. An important question is, therefore: could we, by installing barriers on bridges which are commonly used, reduce the risk of suicide? International research suggests that erecting fences on popular bridges do in fact reduce risk of suicide. Both the general public and Norwegian road authorities are concerned about the question whether we should do so in Norway. However, we might question whether available knowledge transfers to our country. In this article we refer to international research, what has been done in Norway to erect suicide barriers on bridges, and describe a research project undertaken to answer important questions regarding the possibility of saving lives by securing popular bridges in Norway with anti-suicide barriers.

LEVERT: 15.02.13 REVIDERT: 07/05-13 AKSEPTERT: 24/05-13

\section{Kan sikring av bruer forebygge selvmord i Norge?}

Hvert år tar en rekke mennesker livet sitt i Norge ved å hoppe fra et høyt sted. I perioden 2000-2011 har til sammen 324 mennesker tatt sitt eget liv ved utsprang fra høyt sted i Norge (Statistisk sentralbyrå, 2013). I gjennomsnitt var dette 27 selvmord pr. år. I 2011, som er det siste året vi har slik oversikt fra, tok 37 mennesker livet sitt på denne måten, noe som utgjorde $6 \%$ av alle selvmord dette året. Tilgjengelig statistikk spesifiserer ikke hvor disse personene har hoppet fra. Rapporter om enkeltstående hendelser gir imidlertid grunn til å anta at selvmord ved hopp fra bruer representerer en betydelig andel av alle selvmord ved utsprang. Et spørsmål er derfor om vi, ved å installere høye gjerder eller andre sikringstiltak på utsatte bruer, kan forebygge selvmord? Dette er nå en viktig problemstilling som både er oppe i den offentlige debatten og hos vegmyndighetene i Norge.

\section{Hva kjennetegner bru som selvmordssted?}

Høye og spektakulære bruer på velkjente steder, ofte i nærheten av byer og tettsteder, har en tendens til å bli valgt som sted for utsprang. Slike bruer kan oppnå en status som selvmordssted i lokalbefolkningens bevissthet, og det har vært beskrevet en viss psykologisk "dragning" til slike steder. Enkelte bruer er således mer utsatt for selvmord ved utsprang enn andre, noe som ble vist i en svensk studie der alle selvmord ved utsprang fra bru i to geografiske regioner i perioden 1983 -1997 ble gjennomgått. Totalt 27 bruer var blitt brukt til utsprang, men nesten halvparten av selvmordene fant sted fra tre bruer (Lindqvist et al., 2004).

Fokus i media på utsatte bruer bør unngås av hensyn til risiko for såkalte smitteeffekter (Beautrais \&t Gibb, 2009). At slike smitteeffekter kan forekomme er blant annet vist i forhold til Golden Gate Bridge i San Francisco. Denne brua er antakelig verdens mest kjente selvmordssted, og er i alle fall det sted der en har registrert flest selvmord ved utsprang. Lenge ble det registrert omlag 20 selvmord årlig fra brua (Blaustein \&t Fleming, 2009). I perioden 2006-2010 var dette økt til over 30 per år (Whitmer \&t Woods, 2012). På bakgrunn av bruas ikoniske status og at den ligger $i$ et befolkningstett område, søker mange til brua for å ta livet sitt. Flere av dem som har hoppet fra Golden Gate Bridge har passert over nærliggende Bay Bridge, som er en massiv, kjedelig og langt mindre berømt brukonstruksjon. Etter mange års diskusjon har en nå besluttet å sikre Golden Gate Bridge med fysiske barrierer, men finansiering er ikke avklart (Blaustein \& Fleming, 2009;

Reisman, 2012).

The Clifton Suspension Bridge i Bristol, England, er også et sted der det er gjennomført mange selvmord. Gunnell og Nowers (1997) fant at i perioden 19741993 hadde i gjennomsnitt 6 personer hoppet fra brua hvert år; disse bodde i gjennomsnitt 7,3 km fra brua. I dette området nær Clifton Suspension Bridge var det forholdsvis flere som brukte hopp fra bru som selvmordsmetode sammenliknet med Wales og England for øvrig. Gunnel og Nowers sin studie var et viktig grunnlag for beslutningen i 1998 om å sette opp barrierer på brua.

\section{Hva vet om vi personer som tar selvmord ved hopp fra bru?}

Vi har begrenset og usikker kunnskap om hvorvidt de som tar sitt eget liv ved utsprang fra bru skiller seg som gruppe fra andre som tar livet sitt. Noen studier har funnet høyere psykisk sykelighet, andel med rusavhengighet eller lavere yrkesdeltakelse sammenliknet med personer som tar livet sitt ved andre metoder (Gunnel et al., 2005; Reisch, Schuster \& Michel, 2008; Glasgow, 2011). 


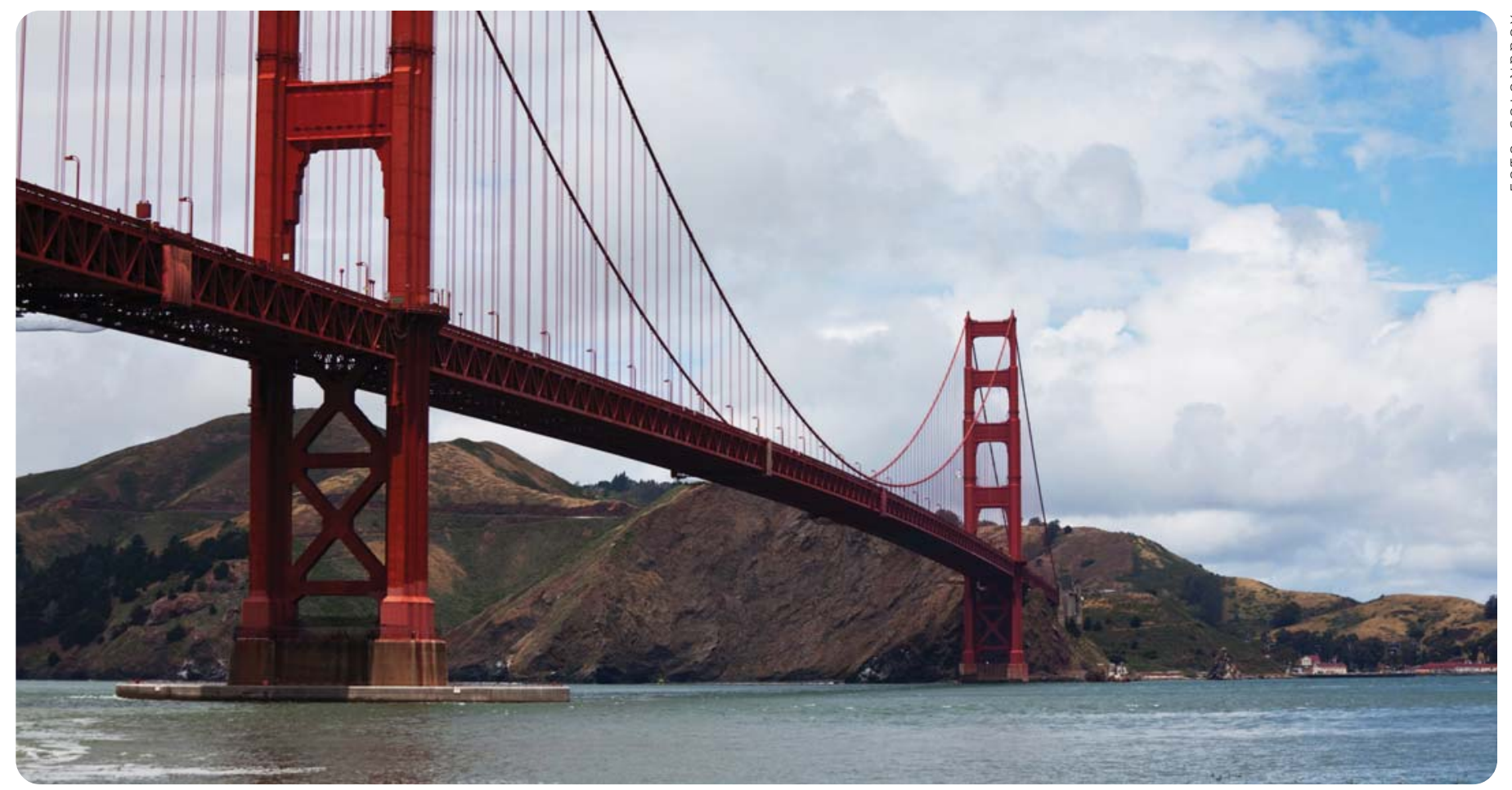

Golden Gate Bridge

Andre studier har ikke funnet slike sammenhenger (Bennewith et al., 2011). Bruer i nærheten av psykiatriske sykehus ser ut til å ha høyere andel av mennesker med alvorlig psykisk lidelse blant dem som tar livet sitt ved utsprang fra brua (Gunnell \&t Nowers, 1997; Beautrais, 2001).

\section{Sikring av bru, en begrensning i tilgang til metode}

Tilgjengelighet er en viktig faktor for valg av selvmordsmetode. Grad av psykisk smerte og intensiteten i de uutholdelige følelsene svinger. Når denne smerten er på sitt mest intense, kan den gi opphav til en faktisk selvmordshandling dersom metoden er lett tilgjengelig. Men et slikt nivå av smerte varer som regel ikke i lang tid av gangen (Rudd, Trotter \& Williams 2009). Ofte vil trangen til å ta sitt eget liv eksistere samtidig med en trang til fortsatt å leve (Jenkins \& Singh, 2000). En selvmordshandling opptrer ofte impulsivt og i en situasjon med en tilgjengelig metode (Mann et al., 2005). Dersom det tar lang tid å iverksette handlingen, vil følelsen ofte ha blitt mindre intens og faren for selvmord også blitt redusert. En begrensning i tilgang på metode kan derfor forebygge selvmord.

I forskningen om metodetilgjengelighet har en i hovedsak studert selvmord ved bruk av skytevåpen og ved forgiftning (medikamenter, plantevernmidler, gass) (Lenaars et al., 2000). Sarchiapone og medarbeidere (2011) konkluderer i sin over- siktsartikkel at begrensning i tilgang til metode er særlig effektiv der hvor metoden er hyppig brukt, svært dødelig, allment tilgjengelig og ikke lett kan erstattes av andre lignende metoder. Det er kjent at flere spektakulære bruer er hyppig brukte selvmordssteder. Hopp fra høy bru er svært dødelig, og ikke minst allment tilgjengelig. Hvorvidt det er mulig å erstatte metoden med andre lignende metoder forutsetter i stor grad at det finnes alternative steder for utsprang i nærheten.

En interessant studie av Marzuk og medarbeidere (1992) har sett på sammenhengen mellom bruk av selvmordsmetode og metodetilgjengelighet. Studien viste at det mellom områder i New York City var forskjeller både i forekomst av selvmord og hvilke selvmordsmetoder som ble benyttet. Forskjellene kunne relateres til ulikheter mellom disse bydelene når det gjaldt metodetilgjengelighet. For eksempel var det relativt lik forekomst av selvmord ved hengning; en metode som ble vurdert å være likt tilgjengelig i ulike bydeler. Selvmord ved hopp fra høy bygning varierte derimot med forekomst av høye bygninger i de aktuelle områdene.

Vil sikring med fysiske barrierer, som gjør utsprang vanskelig, redusere risiko for selvmord på utsatte bruer? Eller vil den selvmordsnære finne andre metoder eller andre steder, noe som dermed reduserer betydningen av slik sikring? Finnes det eventuelt andre tiltak på slike bruer som kan ha tilsvarende forebyggende virkning?

\section{Internasjonal forskning om} betydningen av brusikring

I absolutte tall er det relativt få som tar livet sitt ved hopp fra bruer. Betydningen av brusikring er derfor vanskelig å dokumentere. Noen undersøkelser underbygger likevel oppfatningen at sikring av bruer redder liv. Når bruer som tidligere har vært brukt til selvmord blir sikret, slik at det blir vanskeligere å hoppe fra brua, reduseres antall selvmord fra denne brua betydelig (Beautrais et al., 2009; Sinyor \&t Levitt, 2010). For å vurdere effekten av slik sikring må vi også undersøke om det har skjedd en overgang til andre metoder eller steder, såkalt metodesubstitusjon. Studier fra henholdsvis The Clifton Suspension Bridge i Bristol og The Duke Ellington Bridge i Washington viste at en nedgang i antall selvmord ved aktuelle bruer ikke førte til økning i selvmord ved utsprang fra andre steder (Bennewith et al., 2007; O'Carrol \& Silverman, 1994).

Sinyor og Levitt (2010) fant derimot i sin studie at sikring av Bloor Street Viaduct i Toronto hindret selvmord ved utsprang fra brua, men det totale antall selvmord ved utsprang fra høyt sted ble ikke redusert tilsvarende i det aktuelle området.

Pelletier (2007) fant i sin studie at brusikringen på The Memorial Bridge i Maine, USA, hadde selvmordsforebyggende effekt. Studien gjennomgikk alle selvmord i perioden 1960-2005, henholdsvis 22 år før og 22 år etter at sikkerhetsgjerder ble satt 
opp i 1983. Etter sikringen av brua var det ingen gjennomførte selvmord fra brua. I studien så man også på alle gjennomførte selvmord ved utsprang fra høye steder, samt selvmordsratene fra hele området for samme periode. Det var ingen indikasjon på økning av selvmord ved utsprang fra andre steder eller ved bruk av andre metoder.

Av etiske grunner kan en ikke fjerne sikkerhetsgjerder for å studere nærmere hvilken betydning disse har hatt for å forebygge selvmord. Men i et naturlig eksempel ble slike gjerder, til tross for sterke protester fra helsemyndigheter, fjernet fra Grafton Bridge i Auckland i New Zealand. Det oppstod en markert øning av selvmord fra denne brua etter at sikkerhetsgjerdene var blitt fjernet.

Mange av dem som hoppet var pasienter ved et nærliggende psykiatrisk sykehus, dvs. en utsatt gruppe (Beautrais, 2001). I den samme perioden var det en nedgang i antall selvmord ved hopp fra høyt sted i andre deler av byen. I en gjennomgang av gjennomførte selvmord for årene 19911995 der gjerdet var på plass, 1997-2002 hvor gjerdet var fjernet, og 2003-2006 der nytt gjerde på plass, fant Beautrais og medarbeidere (2009) at antall selvmord økte drastisk i perioden hvor sikringen var fjernet. Etter at nytt gjerde var montert, var det ingen gjennomførte selvmord fra brua.

Få som hopper fra The Golden Gate Bridge overlever (Blaustein \& Fleming, 2009). Men personer som har overlevd forsøk på selvmord ved å hoppe fra bru vil vanligvis ikke ta livet sitt seinere (Gunnell \&t Nowers, 1997). I 1978 så en på hvordan det hadde gått med 515 personer som hadde blitt hindret i å hoppe fra Golden Gate-brua i gjennomsnitt 26 år etter selvmordsforsøket. Av de som var blitt stoppet i sitt forsøk på å hoppe, var det $94 \%$ som fortsatt var i live eller var død av andre årsaker enn selvmord (Seiden, 1978). Også dette støtter oppfatningen om at sikring av bruer reduserer risiko for selvmord.

Bruer sikres vanligvis ved å sette opp fysiske barrierer som gjerder eller sikkerhetsnett. Forskningen som her er referert gjelder slike tiltak. En har også forsøkt å overvåke utsatte bruer, for eksempel

Golden Gate Bridge, med kamera eller patruljerende vakter, eller å sette opp skilt med opplysning om hvor en kan få hjelp og nødtelefoner. Slike sikkerhetstiltak er nesten ikke evaluert, og de erfaringer som foreligger gir usikkerhet om slike tiltak alene har betydning (Beautrais \& Gibb, 2009).

\section{Erfaringer fra Norge}

I Norge vet vi lite om hvor mange som tar sitt liv ved utsprang fra bru, hvilke bruer som benyttes eller hva som karakteriserer dem som benytter denne metoden. Fire norske bruer er sikret i form av høyere rekkverk. På en femte bru er sikringsarbeidet påbegynt (Aga, 2012). Vegdirektoratet vurderer kontinuerlig hvorvidt ytterligere bruer bør sikres. Fredrikstadbrua og Tromsøbrua ble sikret i henholdsvis 2004 og 2005. Det er ikke gjort systematisk registrering av selvmord og fors $\varnothing \mathrm{k}$ på å hoppe fra Fredrikstadbrua før og etter sikring. I Tromsø derimot har Regionalt ressurssenter om vold, traumatisk stress og selvmordsforebygging (RVTS) Nord, i samarbeid med politiet, registrert hopp, annen selvmordsrelatert aktivitet og gjennomførte selvmord før og etter sikring. Erfaringer så langt fra Tromsø indikerer at sikring av brua har redusert antall selvmord (Berntsen \& Larssen, 2011). I løpet av de 5 første årene etter sikringen har selvmordsaktivitet økt på den nærliggende Sandnessundbrua. Gjennomførte selvmord fra de to bruene samlet sett er imidlertid fortsatt lavere enn før sikringen av

Tromsøbrua. Videre kommer det frem av rapporten at gjerdet på Tromsøbrua ikke alltid hindrer en person fra å hoppe. Liv reddes likevel fordi gjerdet forsinker personer tilstrekkelig til at forbipasserende kan oppdage hva som skjer, og redningspersonell tilkalles slik at de kommer på plass på et tidligere tidspunkt. Også Bennewith og medarbeidere (2011) viser til erfaringer fra Clifton Suspension Bridge, der sikkerhetsgjerder bidrar til at ansatte ved brua får bedre tid til å nå fram til personer som forsøker å hoppe, og gjennom dette redder liv.

\section{Økonomiske og etiske aspekter ved sikring av bru}

I Norge har vi et høyt antall bruer, mange av dem er spektakulære og lett tilgjengelig for allmennheten. Ved nybygging av bru tas i dag selvmordsforebyggende hensyn, blant annet i form av høyere rekkverk. $\AA$ sikre allerede eksisterende bruer er imidlertid kostnadskrevende, samt gir byggtekniske og estetiske utfordringer. På den annen side er redningsaksjoner etter fullført hopp svært kostnadskrevende, og ikke minst en stor belastning for pårørende, redningspersonell og lokalbefolkningen. Hvert liv som går tapt er i seg selv uerstattelig og medfører sorg og smerte for pårørende og deres nettverk.

Alt dette fremmer spørsmål om hvordan samfunnet skal prioritere de midler som er til rådighet til forebygging. Eksempelvis er det en pågående diskusjon om hvordan man skal finansiere sikringen av Golden Gate Bridge. Dette til tross for at en nylig publisert kostnad/nytte-analyse sannsynliggjør at sikring av denne brua er en svært lønnsom investering sett fra et samfunnsøkonomisk perspektiv (Whitmer \&t Woods, 2012).

Gjennom evalueringer av allerede iverksatte sikringstiltak vil man kunne få kunnskap som gir klarere indikasjoner på virkning av brusikring. Hvor sikker kunnskap må vi ha for å kunne forsvare de $ø$ øonomiske kostnadene ved å sikre allerede eksisterende bruer? Kan vi la utsatte bruer være usikret dersom det er stor sannsynlighet for at enkeltindivider kan hindres fra å ta sitt liv? Dette er svært vanskelige etiske dilemma der det ikke finnes enkle svar.

\section{På bakgrunn av forskning og erfaring kan vi oppsummere:}

Vi har begrenset kunnskap om forekomsten av selvmord ved utsprang fra bru i Norge. Den internasjonale forskningen er begrenset, og betydningen av brusikring i et selvmordsforebyggende perspektiv er vanskelig å vise gjennom forskning da det relativt sett er få som tar livet sitt på denne måten. 
På bakgrunn av eksisterende forskning og erfaringer fra andre land, anbefales imidlertid brusikring som tiltak for å forebygge selvmord (Beautrais \& Gibb, 2009). Dette medfører at bruer som bygges idag bør bli sikret slik at det er vanskelig å hoppe fra dem. Videre anbefales sikring av eksisterende bruer som er kjente selvmordssteder. Spesielt skal en være oppmerksom på bruer som er spektakulære, bruer i tettbygde strøk eller nær psykiatriske sykehus.

Norge har en geografi og demografi som skiller seg fra mange andre land. Befolkningen er spredt, og grunnet vår geografi har vi mange bruer. Til tross for dette er selvmord ved bruk av skytevåpen og hengning hyppigst benyttet (Statistisk sentralbyrå, 2013). Vi kan derfor ikke uten videre overføre forskningsresultater fra andre land til Norge. For å finne ut mer om hvordan vi kan hindre tap av liv ved sikring av utsatte bruer, er det helt nødvendig å se nærmere på hvordan dette fenomenet arter seg i Norge. En kartlegging av hvilke bruer som benyttes ved utsprang vil være avgjørende for at eventuelle tiltak kan settes inn på riktig sted.

Slike tiltak bør i neste omgang evalueres for sin mulige evne til å redusere forekomst av selvmord ved utsprang.

Forfatterne av denne artikkelen arbeider nå med et forskningsprosjekt som stiller spørsmålet: Er sikring av bru et aktuelt selvmordsforebyggende tiltak i Norge? Dødsmeldinger for perioden 1999-2010 skal gjennomgås for å undersøke hvor mange som har tatt sitt eget liv ved utsprang fra bru og hvilke bruer som er mest utsatt (Universitet i Oslo, 2012). Prosjektet har som mål å gi ny kunnskap om fenomenet selvmord ved utsprang fra bru, og med denne kunnskapen belyse behovet for sikring av bru som selvmordsforebyggende tiltak i Norge. Resultater forventes å foreligge i løpet av et år.

\section{Referanser}

Aga, F. (2012, 3.des) Krever bedre selvmordssikring på bruer. Byggeindustrien, Hentet 05.02.13 fra http:// www.bygg.no/2012/12/97884.0

Beautrais, A., Gibb, S.J., Fergusson, S.M., Horwood, L.J. \&t Larkin, G.L. (2009). Removing bridge barriers stimulates suicide: an unfortunate natural experiment. Aust N Z J Psychiatry, 43:495-97.

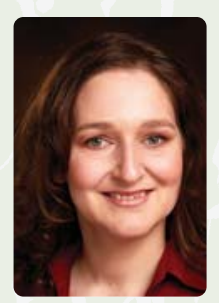

Aleksandra Sæheim er sosionom med erfaring fra sosialtjeneste, barnevern og forebyggende helse. Hun er koordinator for rus- og kriminalitetsforebyggende arbeid i Ski kommune. Hun er for tiden mastergradsstudent i psykososialt arbeid med studieretning selvmordsforebygging ved UiO/NSSF.

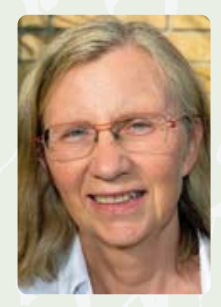

Ingebjørg Hestetun er psykologspesialist og arbeider ved Barne- og ungdomspsykiatrisk seksjon ved Sykehuset Telemark. Hun har vært ansatt ved NSSF og blant anna arbeidet med forebygging av selvmord ved begrensning av tilgang til metoder.

Beautrais, A. \& Gibb, S. (2009). Protecting bridges and high buildings in suicide prevention. I Wasserman, D. \& Wasserman, C. (red) (2009): Oxdford textbook of suicidology and suicide prevention: a global perspective (s. 563-7), Oxford: Oxford University

Beautrais, A. (2007). Suicide by jumping. A review of research and prevention strategies. Crisis 2007; Vol 28(Suppl. 1):58-63.

Beautrais, A. (2001). Effectiveness of barriers at suicide jumping sites: a case study. Aust N Z J Psychiatry, 35:557-562.

Bennewith, 0., Nowers, M. \&t Gunnel, D. (2011) Suicidal behaviour and suicide for the clifton Suspension Bridge, Bristol and surrounding area in the UK: 1994-2003. Eur J Public Health. 21(2):204-8, 2011 Apr

Bennewith, O., Nowers, M. \& Gunnel, D. (2007). Effect of barriers on the Clifton Suspension Bridge, England, on local patterns of suicide: Implications for prevention. Br J Psychiatry. 190, 266-267.

Berntsen, G. \& Larssen, M. (2011). Evaluering av sikringstiltak på Tromsøbrua etter fem år. Rapport Regionalt ressurssenter om vold, traumatisk stress og selvmordsforebygging, RVTS Nord. Lastet ned 16.11.11 fra http://nord.rvts.no/Details.asp?art=Evaluering+ av+sikringstiltak+p\%E5+Troms\%F8brua+etter+fem $+\%$ E5rEtaid $=936$

Blaustein, M. \& Fleming, A. (2009). Suicide from the Golden Gate Bridge. Am J Psychiatry. 166(10):1111-6.

Glasgow, G. (2011). Do local landmark bridges increase the suicide rate? An alternative test of the likely effect of means restriction at suicide-jumping sites. Soc Sci Med. 72(6): 884-9.

Gunnell, D., Nowers, M. \& Bennewith, O. (2005). Kan selvmord ved hopping forhindres? Suicidologi, 10(2), 15-17.

Gunnell, D. \& Nowers M. (1997). Suicide by jumping. Acta Psychiatr Scan, 96:1-6.
Jenkins, R. \& Singh, B. (2000). Suicide prevention strategies. I Hawton K. \& van Heeringen K. (red) (2000): The international handbook of suicide and attempted suicide (s.597-615), Chichester: John Wiley et sons, Itd

O'Carroll, P.W. Ct Silvermann, M.M. (1994). Community suicide prevention: The effectiveness of bridge barriers. Suicide Life Threat Behav. 24(1), 89-99.

Leenaars, A.A., Cantor, C.H., Connolly, J., EchoHawk, M., Gailiene, D., Zhao, X.H. et al. (2000). Controlling the environment to prevent suicide: International perspectives. Can J Psychiatry, 45: 639-644.

Lindqvist, P., Jonsson, A., Eriksson, A., Hedelin, A. \& Bjørnstig, U. (2004). Are suicide by jumping off bridges preventable? An analysis of 50 cases from Sweden. Accid Anal Prev 36:691-694.

Mann, J.J., Apter, A., Bertolote, J., Beautrais, A., Currier, D., Haas, A., Hegerl, U., Lonnqvist, J., Malone, K., Marusic, A., Mehlum, L., Patton, G., Phillips, M., Rutz, W., Rihmer, Z., Schmidtke, A., Shaffer, D., Silverman, M., Takahashi, Y., Varnik, A., Wasserman, D., Yip, P. \& Hendin, H. (2005). Suicide prevention strategies: a systematic review. JAMA 26;294(16):2064-74.

Marzuk, P.M., Leon, A.C., Tardiff, K., Morgan, E.B., Stajic, M. \&t Mann, J.J. (1992). The effect of access to lethal methods of injury on suicide rates. Arch Gen Psychiatry 49, 451-458.

Pelletier, A. R. (2007). Preventing suicide by jumping: the effect of a bridge safety fence. Inj Prev 13:57-59.

Reisch, T., Schuster, U. \&t Michel, K. (2008). Suicide by jumping for bridges and other heights: Social and diagnostic factors. Psychiatry Res 161, 97-104. Reisman, W (2012, 26.mai). Golden Gate Bridge suicide barrier could be close after decades advocacy. The Examiner. Lastet ned 14.02.13 fra http://www. sfexaminer.com/local/2012/05/golden-gate-bridgesuicide-barrier-could-be-close-after-decades-advocacy Rudd MD., Trotter DRM. \&t Williams B. (2009). Psychological theories of suicidal behaviour. I Wasserman, D. \& Wasserman, C. (red): Oxford textbook of suicidology and suicide prevention: a global perspective (s. 159-164), Oxford: Oxford University.

Sarchiapone, M., Mandelli, L., losue, M., Andrisano, C. Et Roy, A. (2011). Controlling Access to Suicide Means. Int. J. Environ. Res. Public Health 8:4550-62.

Seiden, R.H. (1978). Where are they now? A followup study of suicide attempters from the Golden Gate Bridge. Suicide Life Threat Behav. 8(4):203-16.

Sinyor, M, \& Levitt, A.J. (2010). Effect of a barrier at Bloor Street Viaduct on suicide rates in Toronto: natural experiment. BMJ $341: c 2884$

Statistisk sentralbyrå (2013). Tabell 08877: Selvmord, etter kjønn, alder og dødsmåte. Lastet ned 03.02.13 fra http://statbank.ssb.no/statistikkbanken/Default _FR.asp?PXSid=0\&nvl=true\&tPLanguage $=0$ ettilside $=$ selectvarval/define. asp\&tTabellid $=08877$

Universitetet i Oslo (2012). Nasjonalt senter for selvmordsforskning og forebygging. Hentet $05.02 .13 \mathrm{fra}$ http://www.selvmord.no/Forskning/NSSFs-forskningsprosjekter/Andre-forskningsprosjekter/Sikring-av-broer

Whitmer \& Woods (2012). Analysis of the Cost Effectiveness of a Suicide Barrier on the Golden Gate Bridge. Crisis 21:1-9. 